\title{
Impact of Problems Associated with Scheduling and Capacity Planning of a Production Process - An Overview
}

\author{
Sunday A. Afolalu ${ }^{1}$, Omolayo M. Ikumapayi ${ }^{2 *}$, Remilekun E. Elewa ${ }^{1}$, Ademola Abdulkareem ${ }^{3}$, Moses E. Emetere ${ }^{4}$,Samuel \\ O. Ongbali ${ }^{1}$, Olamma U. Iheanetu ${ }^{5}$ \\ ${ }^{1}$ Department of Mechanical Engineering, Covenant University, Ota, 112233, Nigeria. \\ ${ }^{2}$ Department of Mechanical and Mechatronics Engineering, Afe Babalola University, Ado Ekiti, 360101, Nigeria \\ ${ }^{3}$ Department of Electrical and Electronic Engineering, Covenant University, 112233, Nigeria. \\ ${ }^{4}$ Department of Physics, Covenant University, Ota, 112233, Nigeria \\ ${ }^{5}$ Department of Computer Science, Covenant University, Ota, 112233, Nigeria
}

\begin{abstract}
Production is one of the most important activities which guarantee the continued existence of man; however, it comes with its challenges which make it very difficult to meet up the consumer's demand. In this regard, the system is required by production and manufacturing companies, human resources, and materials to be enhanced by scheduling and planning of production. In addressing this problem of scheduling over a mid-term possibility, material flow and production objectives should be forecast by solving the problems of planning. Only when the production planning problems have been solved then scheduling problems could be addressed. In this work, we relate scheduling with capacity planning in relation to the production of goods and services. Also reviewed the common problems associated with the industry and how they are overcome.
\end{abstract}

\section{Introduction}

The production process is the combination of a good or service via the use of measurable input and immeasurable input here by generating output which has value for consumption through donating to individual efficacy [1]. Producing companies now have a new expansion direction due to the new trends of sustainable development, the increase in manufacturing efficiency, and the rapid development of industries [2]. The combination of product losses and processing yields makes up raw material efficiency. In and around a processing activity the amount of raw material lost makes it distinguished by the amount of yield used which are determined by technological characteristics of the process and can be achieved through production scheduling which is the scheduling of machines and operations [3].

Important parts of supply chain management are scheduling and Production planning, strategic and operational decisions are carried out at the boundary between operations and sales. For forthcoming periods (such as days or weeks), the inventory qualities and production are determined, sequencing of production quantities, timing, and the actual task assignments within those time periods are also determined [4].

Among many planning roles in the industrialized sector is Scheduling of operations, Due to interruptions or arrival of new information in the scheduling process, finding a schedule is only part of the whole system [5].
There is a need for rescheduling when current schedules are becoming worse or even possible. This rescheduling makes it difficult for capacity planning to be effective thereby breaking the bridge between the producer and the consumers [4]. Capacity planning is the process of meeting changing demands for its products by determining the production capacity needed by an organization without wasting resources through Forecast on how they are going to match what is required. In order tofulfill the requirements of a market these factors all impact each other, the capacity an operation can provide depends largely on the ability it has to evaluate the options it has either to decrease or increase it [6]. The outdated methods are becoming superseded due to the introduction of capacity planning causing a rise in a competitive environment which forces An Increasing number of Industrial companies to adapt to this method. Capacity planning involves the fluctuation of market cost leading to efficient adjustments, shorting delivery times, and Improves due date observation [7]. Material planning activities are the backbone of the planning process which are the input/output (I/O) control, master production scheduling (MPS), and MRP [7].

*Correspondingauthor:ikumapayi.omolayo@abuad.edu.ng 


\section{Production Flow Concept}

The production process is a flow concept of creating output through time and space which adds value to the function of individuals, production is measured as a rate of output/period of time. Production is divided into three parts which are the methods, goods, and services that are formed, the value of goods and services produced, the progressive and dimensional distribution of goods or services produced [8]. Due to challenges encountered by producers, causing resources and time to be spent thereby reducing the efficiency of the process flexibility, data challenges, training (skill improvement), and security [9]. flexibility at the production level are required for individualization and customization in a cost-effective manner, which is most needed at the process level, the environment of production should be flexible, as time goes on a separate department is set aside for systems at the production level and Traditional processes due to the introduction of new technology which is better than the presently used technology at the shop floor level which does not support the process flexibility and is in satisfactory [10]. In the data energetic world, collection and generation of data are important, data can be extracted from the machine sensors in form of quality data, product data infrastructure data, process data, plant data, logistics data,and data from partners [11]. New methods for processing, management, and storing of such data are required also to use and gain the actual benefits from the data, new visualization techniques, algorithms, products, and models are required [12]. Companies are facing a shortage of skilled staff due to various factors. One of the major factors is the introduction of modern equipment which makes the manufacturer send people for training, which takes time and to keep the hired persons within the organization, as younger ones want to have incentives, promotion or prefer to change jobs frequently [13]. Process integration has become quite difficult right from strategy to production, service, and response from customers due to numerous technological standards, approaches, and boundaries with distinctive characteristics within the production systems [11]. The enhancement in the product and higher customer contentment is derived due to customer's response or customization directly in the manufacturing process, also the Optimization of logistic for overproduction cases and out of stock helps in the eradication of income losses [14] after a certain time planned maintenance are carried out by Manufacturing companies to prevent unwanted breakdown based on a number of products processed, operating hours or after a certain time, the operating condition in which machine operates are recorded regularly due to the sensors in the machine which generate a huge amount of data, the data collected during maintenance goes a long way in finding a solution to the machine problems [13].

\subsection{Scheduling Planning}

The optimization and work control, arranging work loading in a production process is known as production schedule. Forward and backward scheduling is used by companies to assign machinery resources and plants, strategies production procedures, procurements of materials, and strategies human capitals [15]. In Forward scheduling planning tasks, the shipping date or the due date is determined from the date resources to become available while Backward scheduling is planning tasks is based on the deadline of the project that is from the due date the process is calculated backward to determine the start date [16]. Production scheduling has various benefits which include leveling, inventory lessening, intensification production effectiveness, decreasing scheduling efforts, precise delivery date quotes, labour load leveling, process change over reduction and so much more [17]. However, scheduling problems are the allocation of limited resources of specific activities in both the manufacturing and services industries that are seeking to optimize one or several objective functions [18]. Simple scheduling problems are as follows, job shop, open shop, and flow shop. The open shop operation has no constraint order; jobs are totally ordered during operation in the job shop. At the flow shop operation, it consists of every machine to precisely each job, the machine receives all jobs in the similar order, in order to estimate their completion time, all jobs most taking place at zero time which applies to all machines on the operation line Each machine cannot be disturbed in the middle of operation because it can only process one job at a time [18].

\subsection{Capacity Planning}

High-capacity operation and smooth balanced load are secured in inventory due to the protection given by production. The strategy of changing customer preferences in long lead times and high costs of customization seems too high for most companies due to its cost for both flexibilities in relation and inventory [19]. The fast and flexible modification takes place in changing demand due to Investments in over-capacity, as the cost of the needed slack resources is too high, this plan of action rarely becomes a feasible option to remain in the competition [20]. The instabilities between overload and idleness experience by distinctive companies can lead to long-lasting capacity problems, the first problems the company experience are bottleneck problems which happens due to substandard due date performance [14], reduce profitability can take place due to cost prompted by coping with overload which is over proportionally high, idle resources secure in the short term scheduling can cause companies to also lose money and long supplier lead times materials management which comes with uncertainties can lead to material management problem [15] lack of serious materials, high inventories and lack of mechanisms, are problems experienced concurrently due to total value-added on procured mechanisms and services, there is a need for 
partly incorporation between capacity planning systems and network of firms which can serve as institutional associations [21]. The significant competitive parameter is a high due date adherence, in other to prevent instability in the mix end products to be produced which can cause the customization which significantly shares of the distributed end products that are exceptional and to prevent creating variable load for departments preparing new items for manufacturing and assembly for the construction department [22]. As the demand for customization fluctuate Periodic capacity deficits are likely to arise in preproduction departments, causing the release of work orders to slow down from the overdue start of manufacturing which makes it a necessity to updated or generated routines and operation times, The Bill of Materials (BOM) and NC-programs [23]. The mix of items to be manufactured is intensely affected by the unbalanced character of the BOMs and the inconsistent mix of end products which makes bottleneck funds often flexible and hard to foresee in manufacturing, it is also tough to start a perfect flow-oriented layout Due to the high quantity of items manufactured in small numbers at uneven intervals, however in view of the use of group technology for enhancement can be realistic knowing that it is difficult to totally remove The difficulties of job-shop production [24]. master production schedule (MPS) systems and material requirements planning (MRP) are simple operational material requirements found in many companies, due to insufficient functions or competence in the systems, most planning and scheduling are based on the capabilities of production planner managers, however, due to MPR flexibility to dynamic demand variation, it is an easily understandable procedure for scheduling production [25].

\section{Problems associated with capacity planning}

i. Difficult manufacturing procedures: in a large production company such electrical company integrated circuit is produced in a large quantity ranging between 400 and 800 steps are required for a complete circle of production, the manufacturing enterprises produce semiconductors using a controlled manufacturing network [26].

ii. Over capacity/inventories: application of high capacity occurs as a result of the security derived from inventory during production leading to a balanced and even load during the process of production. However, most firms experience high cost as a result of these approaches both in lack of finding a head way in fulfilling the customer desire (high cost of customization and extended lead time) and the cost of inventory, change in demand can be adjusted in a flexible way by the investing in over capacity. This approach is hardly feasible due to the high cost of slack resources required to remain in competition with this strategy [27].

iii. Technology and product frequent changes: the product's life circle is becoming very short thereby leading to a state of art in manufacturing, causing a need for new types of tools [28].

iv. Large costs of capacity extension and long lead time: extension of capacity takes time.

v. Profitability is reduced due to the problems associated with bottlenecks because of the inferior performance on due date causing fluctuation between idleness and overload, due to idle resources company loses money and also due to high cost of over proportion induced by managing overloading; [29]

vi. The problem of material management can occur through unable to predict the long contractor time of lead, likewise, the problem of high inventories is also experienced by material management, lack of component and critical materials is also included [30].

vii. Extremely reliable capacity and demand: the ultimatum manufacturing integrated process is unpredictable, due to network and tool breakdowns most manufacturing systems are considered stochastic systems. Therefore, the offer giving by the manufacturing system on capacity is unpredictable therefore they cannot be trusted.

viii. In a situation of general overload, idle resources and volume problems are of great importance [31].

\subsection{The solution to Capacity Planning and Scheduling}

i. The MPS should be kept up to date [13]

ii. In one system there should be an incorporation of various horizons in the order of planning [22]

iii. The order of the customer which is the end product is concerned with the released order and capacity planning [23].

iv. Capacity regulatory [29]

v. Capacity planning for production activities and construction [23]

vi. Contract out restructuring [25]

vii. Early start eradication [32].

\subsection{Relationship between capacity planning and Scheduling}

To fulfill the customer request and solve the scheduling problem over a mid-term possibility material flow and production objective should be forecast by solving the problems of planning. Only when the production planning problems have been solved then will scheduling problems be addressed [34]. MRP, master production scheduling, and the input/output (I/O) are the activities of material planning and they serve as the backbone of the planning process [35]. The capacity limitation does take place due to imprecise 
considerations of non-systematic capacity planning, this means that to evaluate the possibility of plans at the master scheduling level the planner makes use of their personal experience [36].Rough-cut capacity planning (RCCP) shares a common distinctive collection with other techniques due to its simple systematic methods [37].). Materials are aggregated to product groups or end products and capacities to resource groups or production lines [38]. Batch sizes, setups, sequences of operations, and subassembly inventories are being ignored by RCCP to simplify planning [39]. However, during the MPS activity, the accumulated resource utilization can be monitored by the planner systematically. Frequent update of master scheduling gives the planner an advantage, thereby reducing the risk of loading same resources frequently because MPS items are plentiful. In these circumstances, the non-systematic approaches easily produce an overloaded schedule and are liable to human mistakes [40]. Capacity requirements planning (CRP) is responsible for the possibility of materials to be a plan by determining that more detailed methods are used. Both in the subassembly and the end products, CRP calculations are done. Also, separate resources are calculated through routing data and the outcome of sequences in operation, batch sizes, and setups. For the simplification of RCCP, CRP corrects and generates more reliable schedules. Plans are being made to fit the capacity limit by human planner which make the manual work to have a major role however numerous iterations are required to be done during the revisions [41]. The revising plan of iteration into automation is CRP's next step, methods of Finite- loading can be used and are presented in APS systems [42]. The methods in which they are ben used are as follows: first, the ERP system containsa material plan which can be downloaded from. Next, the problem of capacity can be solved using the finite-loading software algorithm without interfering with the due date. Finally, at the ERP system, the revised plan isuploaded, and they are performed [43]. The important benefit associated with the use of automation in leveling of capacity is the reduction in human error. Also, in addition to leveling of capacity, more scheduling of complicated problems can be solved using the algorithms of finite loading. Optimization with tools of finite-loading can be used, for instance, to minimize downtimes or setups or maximizing throughput [44] the quality of the plan depends largely on the technique of most planning parameters and the accuracy of the parameter for planning. However, in some manufacturing environments, the investments in the software and the maintenance of the parameters can be justified, such as capital-intensive production systems [45-46].The methods of planning are not jointly exclusive as an alternative different methods are available to be used concurrently for various purposes, for instance, RCCP can be used by the plant manager for sales plan evaluation, the processes can be supervised by a master scheduler using CRP and finite loading can be performed by production planners on critical resources. The innovation of bringing understanding to these varieties is an essential means of re-planning [47].

\begin{tabular}{|c|c|c|c|c|}
\hline & Job shop & Batch process & $\begin{array}{l}\text { Batch process with } \\
\text { bottleneck control }\end{array}$ & Production line \\
\hline $\begin{array}{l}\text { Process complexity } \\
\square \text { resources } \\
\rightarrow \text { different kinds } \\
\quad \text { of routings }\end{array}$ & 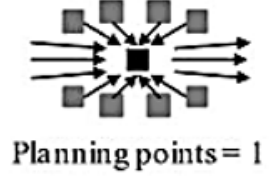 & Planning points $>1$ & Planning points $=1$ & Planning points $=1$ \\
\hline $\begin{array}{l}\text { Task } \\
\text { interdependence }\end{array}$ & Pooled & Reciprocal & $\begin{array}{l}\text { Sequentiala round } \\
\text { the bottleneck }\end{array}$ & Sequential \\
\hline $\begin{array}{l}\text { Non-systematic } \\
\text { capacity planning }\end{array}$ & \multicolumn{4}{|c|}{$\begin{array}{l}\text { Not recommendable for any environment due to high exposure } \\
\text { to human error and va riance in planners' personal competences }\end{array}$} \\
\hline $\begin{array}{l}\text { Rough-cut capacity } \\
\text { planning (RCCP) }\end{array}$ & Fit & \multicolumn{3}{|c|}{ Unfit due to insufficient precision } \\
\hline $\begin{array}{l}\text { Capacity } \\
\text { requirements } \\
\text { planning (CRP) }\end{array}$ & \multirow{3}{*}{$\begin{array}{l}\text { Unfit because the } \\
\text { high variety of } \\
\text { outputs makes the } \\
\text { maintenance of } \\
\text { planning } \\
\text { parameters very } \\
\text { difficult }\end{array}$} & Fit & \multicolumn{2}{|c|}{$\begin{array}{l}\text { Unfit because calculating loads for all } \\
\text { resources is not necessary and more } \\
\text { precise methods are possible }\end{array}$} \\
\hline $\begin{array}{l}\text { Finite loading with } \\
\text { capacity leveling }\end{array}$ & & \multirow{2}{*}{$\begin{array}{l}\text { Unfit because the } \\
\text { subject of finite } \\
\text { loading is not } \\
\text { stationary }\end{array}$} & \multirow{2}{*}{$\mathbf{F i}$} & \\
\hline $\begin{array}{l}\text { Finite loading with } \\
\text { ontimization }\end{array}$ & & & & \\
\hline
\end{tabular}

Fig. 1.The linkbetweencapacity planning and scheduling [48] 


\section{Conclusion}

Capacity planning and scheduling complications of the entire applications regularly features CPR and MPS that suggest the difficulties of methods formed and their applicability is determined by various methods of capacity planning. Capacity planning and scheduling are measured as the production process basic principles (BOM explosion, inventory). These principles are derived from the traditional MRP, moreover the most recent methods these principles are derived from the traditional MRP, moreover, the most recent methods give a higher automation degree for the planning production process, which makes it have great significance. Furthermore, the production planning system alongside scheduling are interwoven and can be interchangeable depending on the type of process of production that is been used at the particular time which enables good flexibility in production systems.

We acknowledge the financial support offered by Covenant University in the actualization of this research work for publication.

\section{References}

1. Liu, Y., Dong, H., Lohse, N., Petrovic, S., Gindy, N., J. Clean. Prod. 65, 87 (2014).

2. Harjunkoski, I., Maravelias, C.T., Bongers, P., Castro, P.M., Engell, S., Grossmann, I.E., Hooker, J., Méndez, C.A., Sand, G., Wassick, J.M., Development Factors Honkomp, 22, 444 (2014).

3. Garcia, D.J., You, F., Comput. Chem. Eng. 81, 153 (2015).

4. Subramanian, K., Maravelias, C.T., Rawlings, J.B., Comput. Chem. Eng. 47, 97 (2012).

5. Samson, O. O., Afolalu, S. A., Ojo, S. F., \& Oladipupo, S. In Journal of Physics: Conference Series, 1378, 032072 (2019).

6. Dugmore, Jenny. Capacity Management. BSI British Standards Institution (2006).

7. Vollmann, T.E., Berry, W.L., Whybark, D.C., Jacobs, F.R., Manufacturing Planning and Control for Supply Chain Management, 5, 34 (2005).

8. Alamdari, Houshang. Metals. 23, 244 (2017).

9. Molfetas, Angelos, Anthony Wirth, and Justin Zobel. IEEE International Congress on Big Data. 10,1109 (2014).

10. Ongbali Samson O, Afolalu Sunday A., Udo Mfon. International Journal of Mechanical Engineering and Technology 9, 2396 (2018).

11. Zhang, Q., \& Tseng, M. M. International Journal of Production Research, 47, 6397 (2009).

12. Amirghasemi, Mehrdad, and Reza Zamani. SpringerPlus 3, 193 (2014).

13. Ongbali S. O., Afolalu S. A. and Udo M. O. IOP Conference Series Materials Science and Engineering 413, 012057 (2018).
14. Rossi, T., Pero, M., International Journal of Operational Research 11, 237 (2011).

15. Afolalu, S. A., Ikumapayi, O. M., Ongbali, S. O., Afolabi, S. O. International Journal of Mechanical and Production Engineering Research and Development (IJMPERD), 10, 1301 (2020).

16. Sun, L., Heragu, S.S., Chen, L., Spearman, M.L., International Journal of Pro-duction Research 50, 921 (2012).

17. Elewa, R. E., Afolalu, S. A., \&Fayomi, O. S. I. In Journal of Physics: Conference Series 1378, 022069 (2019).

18. Chen JC, Chen CW, Lin CJ, Rau H. Comput Ind Eng; 48, 709 (2005).

19. Ikumapayi, O. M., Akinlabi, E. T., Onu, P., Akinlabi, S.A., and Agarana, M.C. Journal of Physics: Conference Series, 1378, 032043 (2019).

20. Jonsson, P., Mattsson, S., International Journal of Operations \& Production Management 26, 971 (2006).

21. Vidoni MC, Vecchietti AR. Comput Ind Eng, 90, 326 (2015).

22. Chen JC, Chen TL, Pratama BR, Tu QF. J IntellManuf, 16,1 (2016).

23. Ongbali Samson O, Afolalu Sunday A., Igboanugo Anthony C. International Journal of Mechanical Engineering and Technology 9(12), 113 (2018).

24. Ikumapayi OM, Akinlabi ET, Adeoye AOM, Fatoba SO. (2021). Material today: Proceedings., 44, 1154 (2021).

25. Samson, O. O., Afolalu, S. A., Ojo, S. F., \& Oladipupo, S. In Journal of Physics: Conference Series 1378, 032072 (2019).

26. Chen JC, Chen YY, Chen TL, Lin JZ. Int J ComputIntegrManuf, 20,1 (2016).

27. Lim SH, Foo CY, Ng KS, Aziz R, Tan RR. J ManufSyst; 33, 639 (2014).

28. Chen JC, Su LH, Sun CJ, Hsu MF. Int J Prod Res; 48, 5729 (2010).

29. Sunday A. Afolalu, Oluwasegun J. Adelakun, Samson O. Ongbali, Abiodun A.Abioye, Oluseyi O. Ajayi, Oloyede Olamilekan. Queueing Theory A Tool for Production Planning in Health Care (2019). Proceedings of the World Congress on Engineering 2019 WCE 2019, London, U.K

30. Kim, B.-G., Choi, B.-C., Park, M.-J. Asia-Pac. J. Oper. Res. 34, 1750017 (2017).

31. Panwalkar, S., Smith, M.L., Koulamas, C. Nav. Res. Logist. (NRL) 60, 46 (2013).

32. Chen JC, Sun CJ, Chen TL. Int J ComputIntegrManuf; 28, 1262 (2015).

33. Ongbali Samson, O., Afolalu Sunday, A., \& Salawu Enesi, Y. Technology, 10, 606 (2019).

34. Öztürk C, Ornek AM. Appl Math Modell; 38, 181 (2014).

35. Chen JC, Chen CW, Lin CJ, Rau H. Computer; 48, 709 (2005). 
36. Salawu, E.Y., Okokpujie, I.P., Afolalu, S.A., Ajayi, O.O. and Azeta, J., International Journal of Mechanical and Production Engineering Research and Development, 8, 915 (2018).

37. Mhiri E, Jacomino M, Mangione F, Vialletelle P, Lepelletier G. IFAC-Papers on Line; 48, 1598 (2015).

38. Chen JC, Fan YC, Chen CW. Int J Prod Res; 47, 4473 (2009).

39. Ongbali Samson O, Afolalu Sunday A., Udo Mfon. International Journal of Mechanical Engineering and Technology 9, 2396 (2018).

40. Moradi, H., \&Shadrokh, S. Computers and Chemical Engineering, 130, 106562 (2019).

41. Afolalu SA, Ikumapayi OM,Abdulkareem A, Soetan SB, Emetere ME, Ongbali SO. Material today: Proceedings., 44, 2895 (2021).

42. Ornek AM. Int J Ind Eng; 23, 26 (2016).

43. Chen JC, Hu SJ, Huang PB, Lin CJ, Chao KJ, Chen CC. Key Eng Mater; 419, 637 (2010).

44. Vollmann, T.E., Berry, W.L., Whybark, D.C., Jacobs, F.R., Manufacturing Planning and Control for Supply Chain Management, 5th ed. McGrawHill Irwin, New York (2005).

45. Elewa, R. E., Afolalu, S. A., \&Fayomi, O. S. I. In Journal of Physics: Conference Series 1378, 022069 (2019).

46. Ikumapayi, O.M., Akinlabi, E.T., Mwema, F.M., Ogbonna, O.S. Materials Today: Proceedings 26, 3275 (2020).

47. Ikumapayi, O.M., Oyinbo, S.T., Akinlabi, E.T., Madushele, N. Materials Today: Proceedings 26, 1532 (2020). 